\title{
The spatial dimension of the triple helix: the city revisited - towards a mode 3 model of innovation systems
}

\author{
Christiane Gebhardt
}

Correspondence: christiane. gebhardt@t-online.de

malik institute, Geltenwilenstrasse

18, CH 9001 St. Gallen, Switzerland
Cities have often been perceived as living laboratories with the right ingredients for a sea change. In fiction the city can be an initiator, a pacemaker or a victim of big transformations - what it will be depends on a specific set of different factors working in a complex system of interrelating variables. In cities we find the intermingling of ideas as well as the spontaneous formation of viable, critical mass of new developments and concepts muddling through. The idea of analyzing city dynamics with a system approach and with an eye to the transformative dimension not only is intriguing, it is highly relevant in times of increasing urbanization, limited resources of our current existence, and new communication technologies. At the dawn of the 6th Kondratieff we analyze data flows to find patterns of connectivity and identify systemic risks to find answers not only for understanding how fuzzy relationships function and systems produce results, but also to find models of new governance and second order intervention to enable cities to organize themselves - in a desired, more sustainable direction. Research is dedicated to facilitate and speed up intelligent intervention into system behavior to enable systems to repurpose themselves (Schwaninger et al. 2006).

Governance of innovation applied to the complex process of city development and to decision-making in stakeholder based city systems is a relatively new and interdisciplinary strain of thought. Research goes beyond the Mode 2 networking institutional relationships and aims at the contours of a Mode 3 model to provide governance and steering information for managing the complexity of a multitude of Mode 2 organization. i.e. of spatially and temporarily overlapping innovation systems on different recursion levels.

The authors of this special issue present cases of different countries and tentatively integrate frameworks such as ecosystems, triple helix university-industry-government relationships, and knowledge clusters in order to analyze the empirical complexity of political, societal, technological and ecological interaction in the evolutionary context of cities. The contributions in this special issue address the relation between Triple Helix relationships and urban agglomerations. In this framework, universities, industries, governments, and citizens are seen as key actors to contribute to the formation of new collaborative environments and identities increasing the innovation capabilities and facilitating continuous improvement (Etzkowitz and Leydesdorff 2000, Kaufmann and Toedtling 2001). The articles demonstrate that the relationship between

(c) 2015 Gebhardt. This is an Open Access article distributed under the terms of the Creative Commons Attribution License (http:// creativecommons.org/licenses/by/4.0), which permits unrestricted use, distribution, and reproduction in any medium, provided the original work is properly credited. 
knowledge producing entities such as universities and the territory has been changing since 1990 (Lawton Smith 2007; Leydesdorff and Deakin 2014 Lazzeroni and Piccaluga 2015). The nexus of innovation and territory takes on a new empirical dimension with a rise of so-called megacities as a predominant urban form. In the concert of institutional stakeholders, knowledge producing universities and their actions are an important power base. However, very rarely are universities the regional organizing element, but rather part of a complex adaptive system with other factors (Umpleby 2009). Unintended consequences occur due to system effects ${ }^{1}$ and city boundaries are blurred. Instead of clear defined roles in triple helix relations ambiguity (Sennet 2012), variety (Umpleby 2009 on Ashby) and redundancy (Schwaninger 2006 on McCulloch and others) are reinstated as explanatory variables for robustness, resilience and sustainability of city systems.

Taken together, the papers point to the limits of current theoretical frameworks of neo-institutionalism as well as to the exhaustion of traditional explanatory models linking territory and innovation networks. The analytical approaches of the empirical studies indicate that the shift of paradigm towards an evolutionary and a system perspective is overdue when it comes to development of local innovation systems. Intervention policies must take into account the complexity, the inter-connectivity and relaxation time of actions in cities. Studies are more and more based on system analysis for the assessment of intervention, governance and the organizing of innovation. Accelerated information and communications technologies drive interaction and new governance models will emerge alongside technological upgrading of urban agglomerations, for instance based on sustainable urban development and $\mathrm{CO}_{2}$ reduction (Mieg 2012, Mieg and Töpfer 2013). Researchers will be challenged by these dynamics of cities, which are triggered by globalization and digitization as well as a range of emergent political practices that involve citizens and social groups (Sassen 2003).

As European programs target technology in regional and urban innovation systems, they reopen the discussion on the old nexus of innovation and territory. The so called Smart City which is still a fuzzy concept will in fact develop as an integrative approach comprising high technology intake, interdisciplinary knowledge creation, social innovation, capacity building, and political concepts. The following collection of papers synthesizes insights from megacity research, sustainability science, as well as from innovation and cluster policy. Last but not least the papers illustrate the spatial dimension of technological and social innovation within the Triple Helix approach and open the window of opportunity to elevate the concept to a mode 3 model.

In Martha Russell's paper on Relational Capital for Shared Vision in Innovation Ecosystems the emphasis is on governance and network orchestration in Metropolitan areas. Russell conducts a comparative network analysis of institutional and personal relationships among business entities, using multiple, exploratory, and data-driven analyses of the three metropolitan areas in the United States: Austin, Texas Metropolitan Area; the Minneapolis/St. Paul (Twin Cities) Minnesota Corridor; and the Greater Metropolitan Area of Paris, France. Her study exemplifies that network orchestration as she calls it - relies on "an integrated understanding of the mechanisms for value creation and capture in the innovation ecosystem context" (Ritala et al. 2013). She states that program managers, policy analysts, business executives, and entrepreneurs must anticipate opportunities beyond their current line of sight to empower and manage the 
process of change. They must deploy high-impact policies that anticipate how alternative or concurrent interventions will improve the likelihood of sustainable change.

An alternative laboratory driven approach to Russell's scenario driven strategy and governance model provides Ary Plonski and his study of practices of five Science and Technology Parks in the Northeast, Southeast and South of Brazil, located in highly dense urban centers with degraded and depressed areas. In his paper on Science and Technology Parks: Laboratories of Innovation for Urban Development - an Approach from Brazil his analytical focus lies on the socio-economic and environmental aspects of so-called innovation habitats' projects in these Parks, which are exemplary Triple Helix locations. His work covers Porto Digital (Recife), Rio Science Park (Rio de Janeiro), Sapiens Technology Park (Florianópolis), Tecnopuc (Porto Alegre), and São Paulo Technology Park Project (São Paulo) in statu nascendi. He suggests that these zones are adequate laboratories of innovation for urban development where large cities can employ strategies that stimulate citizens and use their creativity and knowledge in order to propose feasible innovative solutions to serious urban problems as well as to insert new requirements of the knowledge economy in the planning and restructuring of urban space.

The shortcomings of linear planning and role model transfers demonstrate Raafat Zaini, Dmitriy Lyan and Eric Rebentisch in their paper Start-up research universities, high aspirations in a complex reality: a Russian start-up university case analysis using stakeholder value analysis and system dynamics modeling. They discuss the new research university SkolTech located in the Moscow periphery as a potential change driver of urban and societal development. The Russian project aims at the creation of a new world-class research university, upgrading or merging existing universities and upgrading of Russian technology based industries while at the same time contributing to capacity building in research and science. Employing a system dynamic approach the authors demonstrate the limits of growth models invented in a different context and mollifies high expectations of government policies that are based on the mental model of simply copying old role models such as Boston or Silicon Valley through generous funding and partnerships.

In this line of thinking, Friederike Bellgardt, Jürgen Gohlke, Henriette Haase, Roman Parzonka and Juliane Schicketanz shed light on non-intended consequences of linear planning and elaborate on the empirical reality of stakeholder complexity that goes beyond the scope of the classical triple helix triad. In the paper Triple helix and residential development in a science and technology park: The role of intermediaries they analyze the transformation of Science and Technology Park Berlin Adlershof in Germany into a Science City or a knowledge-based form of urban settlement and housing. The authors employ the triple helix approach not only to study processes of innovation but socio-cultural aspects of urban development. They propose the extension of the triple helix concept that highlights the pivotal role of the intermediary in the planning process to capture the complexity of a living city and to avoid planning shortfalls.

The importance of cultural factors and citizenship for building a more valid theoretical framework is also stressed in the paper Making a humanities town: knowledge-infused clusters, civic entrepreneurship and civil society in local innovation systems by Henry Etzkowitz. He analyzes in a longitudinal study how the Southern Oregon University and 
the Ashland cultural cluster in the US State Oregon grew hand in hand, with the cluster spurring the academic development of its parent. In his paper he elaborates on a knowledge-infused cluster that involves governmental agencies and university, as well as firm actors. He constructs a model for education-focused universities to play a significant role in local economic development through creation of cultural clusters from existing knowledge. In his understanding civil society is the launch pad - as he calls it - for take-off of triple helix university-industry and government interactions. He expands entrepreneurship into a broader conception to map its various forms of commercial, social, cultural and civic entrepreneurship. The convergence of entrepreneurship, triple helix, cluster and civil society exemplified by the Ashland case, provides another category in the world of regional innovation models.

Mark Deakin reflects on the governance of smart cities. He explains smart cities in terms of the social networks, cultural attributes and environmental capacities, the vital ecologies of the intellectual capital, wealth creation and standards of participatory governance regulating their development. In his paper Smart cities: the state-of-the-art and governance challenge he advances the Triple Helix model and resumes that society needs not only to generate intellectual capital, or create wealth, but also cultivate the environmental capacity. In his view ecology and vitality of spaces go hand in hand and depend on the direct democracy of ICTs potential to enable participatory governance.

\section{Endnotes}

${ }^{1}$ for example the rebound effect: Energy efficiency leads through various cycles on prices to an increase in the demand for energy or the dense sprawl where rigid densification strategies lead to loss of connectivity and even poorer neighbourhoods.

Received: 23 June 2015 Accepted: 24 June 2015

Published online: 15 July 2015

References

Deakin M, Leydesdorff L (2014) The triple helix model of smart cities: a neo-evolutionary perspective. In: Deakin M (ed) Smart cities: governing, modelling and analysing the transition. Routledge, London, UK and New York, NY, pp 134-149

Etzkowitz H, Leydesdorff $L$ (2000) The dynamics of innovation: from national systems and "mode 2" to a triple helix of university-industry-government relations. Res Policy 29(2):109-123

Kaufmann A, Toedtling F (2001) Science-industry interaction in the process of innovation: the importance of boundary-crossing. Between systems. Res Policy 30(5):791-804

Lawton Smith H (2007) Universities, innovation and territorial development: a review of the evidence. Environment and planning C. Gov Policy 25:98-114

Lazzeroni M, Piccaluga A (2015) Beyond town and gown: the role of the university in small and medium sized cities. Ind High Educ 29(1):11-23

Mieg HA (2012) Sustainability and innovation in urban development: concept and case. Sustain Dev 20(4):251-263

Mieg HA, Töpfer K (eds) (2013) Institutional and social innovation for sustainable urban development. Earthscan, London

Ritala P, Agouridas V, Assimakopoulos D, Gies O (2013) Value creation and capture mechanisms in innovation ecosystems: a comparative case study. Int. J. Technology Management 63(3/4):244-267.

Sassen S (2003) The participation of states and citizens in global governance. Ind J Global Legal Stud 10(1):5, Article 2

Schwaninger M (2006) Theories of viability: a comparison. Syst Res Behav Sci 23(3):337

Schwaninger M, Janovjak M, Ambroz K (2006) Second-order intervention: enhancing organizational competence and performance. Syst Res Behav Sci 23(4):529, Link

Sennet, Richard THE GUARDIAN. 04.12.2012 Nobody likes a city that is too smart. http://www.theguardian.com/ commentisfree/2012/dec/04/smart-city-rio-songdo-masdar.

Umpleby SA (2009) Ross Ashby's general theory of adaptive systems. Int J Gen Syst 38(2):231-238. doi:10.1080/ 03081070802601509 